\title{
The New "European" Financial Statement and Its Implications in Italy
}

\author{
Mario Nicoliello ${ }^{1} \&$ Simone Lazzini ${ }^{1}$ \\ ${ }^{1}$ University of Pisa, Italy \\ Correspondence: Mario Nicoliello, University of Pisa, Italy. E-mail: mario.nicoliello@hotmail.it
}

Received: December 17, 2018

Accepted: February 23, 2019

Online Published: February 24, 2019

doi:10.5539/ijbm.v14n3p163

URL: https://doi.org/10.5539/ijbm.v14n3p163

\begin{abstract}
The Directive 2013/34/EU has changed the content of the annual accounts, impacting on many items. The paper presents the consequences of the Directive on Italian legislation, analyzing in detail the values that have been modified. The concluding part contains interesting considerations on the whole reform process.
\end{abstract}

Keywords: financial statements, Italy, annual accounts

\section{Introduction}

With the promulgation of Legislative Decree 18 August 2015, no. 139 the national legislature has implemented in Italian law Directive 2013/34/EU of the European Parliament and the Council of 26 June 2013, in accordance with the provisions of Article 1, paragraphs 1 and 3, as well as Annex B of the Law of the European delegation 2013 relative to the second half year (Law of 7 October 2014, no. 154).

In addition to supplementing and amending the civil code and the legislative decree of 9 April 1991, no. 127 - in order to align the provisions on annual financial statements and consolidated financial statements to what is contained in Directive 2013/34 - the Legislative Decree in question also makes amendments to other existing legislative measures, to adapt the content to the requirements of the directive or through the needs for appropriate coordination.

In particular, Legislative Decree 139/2015:

- amends Legislative Decree 26 May 1997, no. 173, regarding annual financial statements and consolidated financial statements of insurance companies, in order to align certain aspects of this specialist discipline to that general one;

- integrates the provisions of Legislative Decree of 29 January 2010, no. 39, regarding statutory auditors, to incorporate the innovations introduced by Directive 2013/34 concerning the content of the judgement expressed by the auditor;

- $\quad$ amends Legislative Decree of 28 February 2005, no. 38 laying down the field of application of the parties responsible for drafting the annual financial statement, individual and/or consolidated, in accordance with the international accounting principles, to take account, with reference to the participating companies of Community Regulation 575/2013 concerning the prudential requirements for credit institutions and investment firms, as well as of the innovations in the financial sector introduced by Legislative Decree 141/2010 in the matter of parties operating in the financial intermediation sector.

The new provisions shall apply starting from administrative periods commencing from 1 January 2016. It was therefore an accelerated process with respect to the previous one. In fact, the transposition of Directive 2013/34 was arrived at in just two years, against the thirteen years elapsed between the fourth EEC directive of 1978 and Legislative Decree no.127 of 1991.

Despite its brevity the process was attended and not devoid of criticality. Already on 19 June 2014 the Ministry of Economy and Finance had published a consultation document in which it stated as "exercising transposition could entail difficulties due to the presence of numerous options not only technical, but especially relating to fundamental choices about the definition of the future accounting system, in particular referring to the different dimensional segments of companies (with relative different information systems) and, more generally, to the theme of the administrative burden arising from the obligation $2014 \mathrm{~s}$ of the budget and to the consequent trade off between quantity and quality of information on the one side and reduction of the administrative burden on the other (MEF, 2014). 
At the end of the process it could be said that the legislator has taken the opportunity to regulate certain operations requiring interventions: from assessment and accounting in the annual financial statement of derivative financial instruments to hedging operations. At the end of the process the innovations are significant. Following the simplification guideline for smaller companies and additional obligations for those of larger dimensions, new mandatory annual financial statement proposals are expected, the criterion of assessment at amortized cost for receivables, payables and securities, the fair value for financial derivatives introduced, as well as the significant general principles and the economic substance.

Therefore, the new rules introduced in the Civil Code will be described analytically below, in particular with respect to the following themes (Nicoliello, 2016):

- principles for the preparation of the annual financial statement;

- the annual financial statement format;

- the cash-flow statement;

- the evaluation criteria;

- the contents of the notes to the accounts;

- the category of small and micro-enterprises.

\section{Principles for the Preparation of the Annual Financial Statement}

Article 2423 has been amended through the introduction of a new paragraph 4 which provides for the possibility of not respecting the obligations of materiality, assessment, presentation and disclosure when their compliance is irrelevant.

With this provision national legislature has transposed the materiality principle introduced by Article 6 (paragraph 1(j) of the Directive. The amendment referred to in article 2423 accompanies the requirement to illustrate in the notes to the accounts the criteria with which the companies have implemented this provision. The text of the rule also reiterates - in line with what has already been explained in recital 17 of the Directive - that the materiality criterion does not in any way call into question the obligations relating to keeping proper accounts.

The introduction of the general principle of materiality led to the elimination - since considered redundant - of references to that principle contained in the specific Civil Code disclosure rules, as well as the rule referred to in number 12 of the first paragraph of Article 2426, a striking example in the application of the materiality principle to the assessment of financial statement items.

The principle of materiality will therefore be applied to both the values entered in the financial statement format and to the information given in the notes to the accounts. One of the practical effects of the principle could be the choice of simplified evaluation criteria with respect to those provided for by law or by national GAAP. For example the evaluation at the amortized cost of the securities, receivables and payables, the application of which in certain cases could prove burdensome for who prepares the financial statement compared to the residual advantages which would arise in terms of the quality of the information. Ultimately the new principle should be understood not as the introduction of an arbitrary right to omit the full recording of company affairs, but as the ability to choose a way to represent them that reconciles the burden resulting from compliance with the accounting rules with the benefits gained by those reading the financial statement (Branciari, Poli, 2009).

In addition to materiality the legislator has also incorporated the principle of substance over form, by amending article 2423-bis with the elimination of the last sentence of number 1, replaced with a new number 1 bis.

On this point it is necessary first of all to emphasize how the directive, among the general principles listed in Article 6, stipulates that the collection and presentation of the financial statement classes should be made taking into account the substance of the transaction or of the contract. The same article, however, has granted the Member States the possibility to exempt companies from this obligation. In the previous version art. 2423-bis recalled the need to take into account, for the purposes of the assessment of financial statement items, the economic function of the asset or liability element considered. In this formulation, however, the code's regulation had aroused some interpretative problem in the application phase. As explained in the explanatory memorandum of Legislative Decree 139/2015 "the concept of economic function of the asset or liability element can evoke the concept of destination and it was debated at length about the actual application scope of the provision. In the public consultation organized by the Ministry of Economy and finance the need to amend the provision was highlighted, in particular by eliminating the reference to the asset or liability entry". 
The new reformulated Article clarifies that reference to the substance should refer not just to the assets or liabilities entry of the financial statement, but to the contract or to the operation, according to a more coherent approach with the provision contained in the directive. Obviously the practical application of the principle of economic substance will be carried out by resorting to national accounting standards.

\section{The Annual Financial Statement Format}

Article 2424 (indexed as "balance sheet content") was amended to adopt the consequences arising from the new discipline on derivatives, on the costs of research and advertising and on own shares.

As regards the first item on the balance sheet, the classes "financial derivative assets" (both among financial fixed assets, and among current assets) and "financial derivative liabilities" (among the provisions for risks and charges) are introduced.

In relation to the costs of research and advertising, the new version of the article in question no longer allows capitalisation, reserving the latter just for development costs.

As regards own shares, their regulation has been amended by providing that they are entered in the financial statement as a direct reduction of net equity, adopting in full what is provided for by Directive 34 which did not allow its inclusion in the fixed assets.

Following the international practice, the Italian legislature has also imposed a ban on the inclusion in the financial statement of treasury shares not intended to remain permanently in the assets of the company, thus solving the doubts about the nature and the regime of availability of the reserve for treasury shares, which disappears from the net assets. On the other hand, from 2016 onwards in net assets the companies will have to indicate the "negative reserve for treasury shares in portfolio".

This is a major amendment which completely changes the scenario up to 31 December 2015. In the previous regulatory provisions - corroborated by the OIC 21 - the treasury shares were entered on the assets side of the balance sheet separately from other shares. In the entry, next to the book value of treasury shares, the total nominal value was indicated; moreover at the moment of recording treasury shares in the assets, a reserve was constituted of equal amount to be entered in net assets under the heading "Reserve for treasury shares in portfolio".

In the balance sheet format, specific detailed items were also introduced relating to relations with companies subject to control by their parent companies (the so-called sister companies). In particular the entries "Shares in companies subject to the control of parent companies", "Receivables from companies subject to the control of parent companies" and "Payables to companies subject to the control of parent companies".

Finally the provisions relating to memo accounts were deleted, whose information - pursuant to Directive 34 are now shown in the notes to the accounts, and references to premiums and discounts have not been eliminated, which from 2016 onward will be considered in the context of evaluation with the method of amortized cost.

Article 2425 (indexed as "Contents of the profit and loss account") is also amended to incorporate the effects on the financial statement items deriving from the amended regulation on financial derivatives. Therefore area $\mathrm{D}$ has been renamed "adjustments to the value of financial assets and liabilities" with the addition of two items: "Revaluations of financial derivatives" and "writedowns of financial derivatives".

Specific classes of detail relating to the relations with companies subject to control by parent companies are then introduced in the income statement. In particular it is necessary to indicate separately the proceeds from shareholding and other income related to "parent companies and companies subject to control by the latter", as well as the amounts owed to them by "parent companies and companies subject to control by the latter".

Moreover, an anything but secondary amendment, following the wording of Directive 34 the legislator has eliminated from the income statement the cost and revenue items relating to the extraordinary section. This is an innovation of no small account that involves a much debated area of the financial statement in the past for the diversity with which companies felt that they could enter or not the result of a given operation in this area rather than in that of usual management.

The legislator has destined the information previously contained in the accounting format to the notes to the accounts. In the descriptive document, therefore, an indication of the amount and nature of the individual elements of cost or revenue of an exceptional amount or impact should be provided.

\section{Cash-Flow Statement}

Article 2423, paragraph 1, of the Civil Code has been amended by providing for the obligation of drafting the 
financial statements, thus following the provisions of Article 4(1) of Directive 2013/34, which allows Member States to impose on companies other than small ones, the drafting of further financial statement documents.

The Italian legislature grasps this opportunity and imposes (it is in fact an obligation and not discretionary) the drafting of the cash-flow statement on medium to large-scale enterprises, a situation already provided for listed companies that apply international accounting standards. Starting from the 2016 financial year the financial statement model of medium to large-scale enterprises will no longer consist of three documents, but four documents:

1. Balance sheet:

2. Profit and loss account;

3. Notes to the accounts;

4. Cash-flow statement.

Micro-enterprises and those who draw up the annual financial statement in abbreviated form are instead exempted from drafting the cash-flow statement.

The presentation of the cash-flow statement will be able to significantly improve the information on the financial situation of the companies. The information on this investigative dimension are in fact not recognizable from reading the other two parts of the financial statements, which focus instead on the balance between assets and income. Already in the past many companies voluntarily prepared a cash-flow statement, drafting it according to the characteristics of the company and according to autonomous formats. From 2016 onwards the new rule contains precise information on the ways of drawing up the prospectus that should indicate the monetary needs of the company, describing in detail the collection and use of funds process.

Unlike what is provided for the other mandatory financial statement formats, the new Article 2425-ter (indexed as "Cash-flow Statement") does not provide for a minimum statement content, but indicates the objectives that the document should aim for. In particular, the regulatory provisions show how the amount and composition of cash availability for the current financial year and for the previous should result from the cash-flow statement. From this originates how the reference variable of the prospectus is represented by cash availability. The new article then explains how the cash flows for the year should be broken down according to whether they relate to the operational, financial, investment activity or relating to equity.

The legislator then follows in full with the indications already indicated by professional practice and by the interpretation (Potito, 1980; Coda, 1986; Farneti, 2002) and merged into the new version of the OIC 10 ("Cash-flow Statement"), which provides specifically for the presentation of cash flows using a format based on variations in liquidity.

In standard conditions companies generate financial resources from two management areas: the current one, which produces liquidity from the recurrence of managerial processes of a recurring and repetitive nature and that of disinvestments, where the liquidity produced is uncharacteristic. Consequently, in order to suitably illustrate the current operating cash flow, it is necessary to explain if operational activities overall establish a cash surplus or a cash requirement. The flow of the operational management, where resources deriving from the characteristic management come together, is therefore the more relevant aggregate to indicate the company's financial-monetary health status.

The cash flow of investments comprises instead the positive and negative variations arising from the purchase and sale of tangible and intangible assets and the financial assets. Cash flow comprises the financial fluctuations which derive from obtaining or from the return of cash availability in the form of risk capital or debt capital (Portalupi, 2015).

\section{The Evaluation Criteria}

Numbers 1, 7 and 8 of article 2426 were amended to allow for the introduction of the method of the amortized cost for the evaluation of receivables, payables and securities. In the case of securities, the new provision makes it clear that the method is only adopted in the case in which the characteristics of the security so permit.

The amortized cost technique - which identifies a configuration of value that is still generally attributable to the historical cost - allows a better representation of the income components linked to the economic affair of the classes of value subject to the evaluation process by providing for the materiality of interest (both from the asset side and from the liability side) based not just on the nominal rate of return, but on the actual operation.

The legislator has referred back to international accounting standards for the definition of amortized cost. 
Essentially the criterion of amortized cost moves from the objective to measure a determined income in the income statement with fixed, financial logic, in the face of an operation that could lead to the inclusion of irregular income/charges over time.

In its new wording, this article in question also requires that the evaluation of the receivables and payables is also carried out taking into consideration the time factor. From this stems the need therefore to proceed with the updating of the receivables and payables that, at the time of initial recognition, either do not produce interest, or generate interest at a rate that is significantly lower than that of the market.

The obligation of consideration of the time factor was not extended to the evaluation of securities, because - as has been explained in the explanatory memorandum to the decree - the latter being mainly bonds issued by private companies or public debt securities, produce - normally - Interest in line with those of the market.

By following the provisions laid down by Directive 2013/34 the legislator then interceded on the criteria of evaluation to amend the regulation on deferred charges and goodwill, specifying how value writebacks on value adjustments relating to goodwill are no longer admitted.

In accordance with the provisions in force until 2015, goodwill could be amortized over a period not exceeding five years, with the possibility of resorting to a longer period of time, anyway not greater than the actual useful life of the goodwill, providing an adequate reason in the notes to the accounts.

With the new regulatory provisions, goodwill will be depreciated according to its useful life and only in exceptional cases where it is not possible to make a reliable estimate, depreciation will be allocated over a period not exceeding ten years.

A similar change has also affected the development costs. In accordance with the provisions in force until 2015, such capitalized expenditure could be amortized over a period not exceeding five years. With the new provisions, long-term utility development costs are depreciated according to their useful life and only in exceptional cases where it is not possible to make a reliable estimate of the useful life of the development projects that have led to the inclusion of costs in the assets, such expenses are amortized over a period not exceeding five years.

The amendment has also affected the valuation of shareholdings with the net equity method. In particular - based on the directive - the new version of Article 2426 makes an explicit reference to the acquisition date of the shareholding to calculate the corresponding value of the net equity of the shareholding to be compared with its purchase cost when the criterion is first applied.

Number 8-bis of article 2426 was also amended, so as to better clarify the fact that the obligation to bring the current exchange rate in line with the financial statement date only exists for the financial statement classes that have a monetary nature. In particular, as regards the criteria for the evaluation of assets and liabilities in foreign currency the legislator - following the provisions of the reformulated OIC 26 - distinguishes between monetary items in foreign currency (asset or liability that involve the right to collect or the obligation to pay, determined or determinable currency amounts at future dates) and non-monetary items (other assets and liabilities that do not meet the definition of monetary items) by providing that:

- for monetary items at the time of the financial statement closure the exchange rate must be revaluated at the date of the end of the financial year;

- For non-monetary items, the values will remain entered in the financial statement based on the historical exchange rates in force on the transaction date.

The introduction of number 11-bis was significant, to regulate - pursuant to the provisions contained in Directive 2013/34 - financial derivatives and hedging operations. The amendment resulted in the inclusion in the Civil Code of specific methods for calculating fair value.

In particular, following the International accounting practice, legislature has provided for a general obligation to list derivatives at fair value, by extending this requirement when the derivative instrument is incorporated in another heading. In the case of derivative instruments used for hedging risks, the rule then provides for a differentiated regime depending on whether the coverage refers to the fair value of the elements in the financial statement or to cash flows or future transactions. In fact, notwithstanding the fair value evaluation of the derivative, in the first case the norm requires evaluation of the element subject to coverage by highlighting the changes in value relating to the hedged risk; in the second case, instead, in the absence of elements to evaluate in the financial statement because the coverage refers to future operations, the effects of the fair value evaluation are shown as a net equity entry. Once the effects of the operation to which it is intended to give coverage are clear, profits or losses accrued on the derivative instrument are recognized in the income statement in such a way 
as to make the fluctuations in value on the element that is the subject of the cover, free of impact.

In the case of financial instruments that do not fall into hedging operations, any gains arising from the fair value evaluation are set aside in a non-distributable reserve. This obligation shall not apply in the case of profits arising from the evaluation of the hedging derivatives, but only on condition that the coverage refers to the elements present in the financial statement and evaluated symmetrically with the hedging derivative.

The legislator has stated that the reserves that are generated due to the effect of the evaluation of derivative instruments to cover cash flows or future transactions, since they do not have a match in the financial statement that offset profits or losses until the hedged flows or transactions appear, are therefore not considered for the purposes of calculating the net assets in the cases provided for by the law on bond issues (art. 2412), distribution of profits to the shareholders (art. 2433), passage of reserves to capital (Art. 2442), the reduction in capital due to losses (art. 2446) and legal limit of capital (Art. 2447). The reserves in question are not available or usable to cover losses.

\section{The Contents of the Notes to the Accounts}

The legislator has also introduced important amendments in the content of the notes to the accounts, implementing them on the structure and content provided for by the directive. In particular: the reference to the costs of research and advertising contained in number 3 of Article 2427 was deleted since the costs are no longer eligible for capitalisation.

Expressions such as "when their amount is appreciable", rather than "if significant", or "are relevant" were then eliminated, as such references are now already included within the context of the more general principle of materiality already commented in the previous paragraphs.

At number 9) Article 2427 the new wording provided for by the directive on the subject of information on commitments, guarantees and contingent liabilities was introduced. This is information previously entered in the memo accounts that the reform has abolished.

At number 13) of the article in question, the information on the composition of extraordinary items in the income statement was deleted, replacing it with information relating to the amount and nature of the individual items of income or expense of exceptional impact or size. This change follows the abolition of the extraordinary area from the income statement. On this point it must be noted how the information on exceptional events can also cover ordinary activities: for example an income earned from a traditional customer following an order considered non-repetitive.

At number 16) of article 2427 the disclosure to provide relating to economic relations that can exist between the company and directors and statutory auditors is detailed. The regulation of article 2399 Civil Code which prohibits the equity relationships that might compromise the independence of the Board of Statutory Auditors remains in place, while the spectrum of information to provide is broadened: for example also prepayments or funding, specifying the interest rate and any amounts refunded.

At number 18) of the aforementioned article reference to the information to be provided on derivative financial instruments issued by the company, is completed with reference also to warrants and options;

New information is then requested in the Notes concerning: the nature and the effects of assets, financial and economic of significant events after the closure of the financial year; the name and registered office of the company which draws up the consolidated financial statements, of the larger and of the smaller group of which the company is part as a subsidiary, as well as the place where a copy of the consolidated financial statements is available; the proposal for the allocation of profits or losses.

An important aspect for the correct preparation of the notes to the accounts is in the provision added to paragraph 2 of article 2427 where the information relating to the items in the balance sheet and income statement are presented according to the order in which items are shown in the balance sheet and in the income statement. Therefore, entering in the note the information in the order with which it is required in the text in the Civil Code, will no longer be allowed.

Ultimately the new document seems simplified with respect to the previous one, although in certain circumstances greater disclosure requirements have been introduced with respect to the current situation, mainly because of amendments to the primary financial statements. 


\section{The Condensed Set of Financial Statements and the Financial Statements for Micro-Enterprises}

Through Legislative Decree of 18 August 2015 no. 139 many changes have also been made to the rules governing the financial statements in abbreviated form contained in article 2435-bis of the Civil Code.

The dimensional parameters are instead unchanged with respect to the past. Companies not quoted on the regulated markets that in the first year or, subsequently, for two consecutive years, have not exceeded two of the following limits can in fact opt for the condensed financial statements:

- total assets in the balance sheet of 4,400,000 Euro;

- revenues from sales and services of 8,800,000 Euro;

- employees on average during the year amounting to 50 .

As regards the changes some provisions contained in the previous legislative requirements were eliminated, and new provisions have been added. More specifically, the provision according to which depreciation and write downs should be explicitly deducted from the intangible and tangible fixed assets entered on the assets side of the balance sheet, was deleted. In the current version "the balance sheet only comprises the items marked in article 2424 with upper-case letters and with Roman numbers is provided for; entries A and D of the assets may be included in item CII; liabilities item E can be included in item D; in the items CII of assets and D of liabilities receivables and payables due after the next financial year must be shown separately".

A quite considerable point is also added, granting exemption from the drafting of the financial statements for companies who draw up a condensed financial statement, for which the financial statement system continues to be made up of three statements: balance sheet, profit and loss account and notes to the accounts. The latter statement is however much more concise than that for medium-large companies. Ultimately, there are changes to the setting of the provisions relating to the notes to the accounts with the new version of the Civil Code. In fact if in the previous version the code indicated negatively the themes that the companies were not to enter in the document, the new regulatory provisions indicates positively - as envisaged by the directive - the information that must be shown.

Reaffirming what has already been provided for in the previous version, the legislator has granted to small businesses that use the condensed financial statement not to draw up the management report in the case in which information concerning the number and the nominal value of the shares owned, purchased and sold is entered in the notes to the accounts.

Finally, a new paragraph is added to give companies who draw up the condensed financial statement the discretion, in derogation from Article 2426 (evaluation through the criterion of amortized cost), to enter the securities at purchase cost, receivables at the estimated realizable value and payables at their nominal value.

It must however be stated how also in the new version of the Civil Code, small companies have the right to enjoy all the simplifications provided for or just some of them. Accordingly where they consider it appropriate these companies may provide additional information with respect to that provided for in article 2435 bis, or have recourse to the provisions of the ordinary financial statements (Pozzoli, 2015).

Decree 139/2015 introduces Article 2435-ter into the Civil Code, which is dedicated to the financial statements of micro-enterprises. Paragraph 1 of the new article indicates the requirements to be able to fall into the simplified scheme, providing that to apply this form of financial statement are companies that in the first year or, subsequently, for two consecutive years, have not exceeded two of the following limits:

- total assets in the balance sheet of 175,000 Euro;

- revenues from sales and services of 350,000 Euro;

- employees on average during the financial year amounting to 5 units.

The first interesting aspect to underline is the choice of the Italian legislature to reduce the thresholds for admission provided for by the directive, behaving in a more restrictive manner in relation to the text of the Community provision. In particular Decree 139/2015 has halved all three maximum quantitative thresholds laid down by the directive.

According to the reformed provisions of the Civil Code, for micro-enterprises the same rules shall apply for the companies who draw up the condensed financial statements, except for the further simplifications provided for in Article 2435-ter. On this point it should be noted that the micro-enterprises are exempted from the drafting of the notes to the accounts if at the foot of the balance sheet is the information provided for by numbers 9 (information on commitments, guarantees and contingent liabilities) and 16 (information on fees, advances and credits granted 
to auditors and directors), paragraph 1 of article 2427 . To this must also be added the information on treasury shares, whose insertion at the foot of the balance sheet allows both the notes to the accounts, and the management report not to be drafted.

In addition for micro-enterprises (this is obligatory and not discretionary) the provisions relating to exemptions for exceptional cases, the rules on the evaluation of derivatives and hedging operations do not apply.

As a result therefore of the changes contained in Legislative Decree of 18 August 2015, no. 139, starting from the 2016 financial year financial statements will be drawn up in four different formats depending on whether the company is quoted or not and depending on its size. In particular the Italian companies quoted on the regulated markets will draw up their annual financial statements complying with international accounting standards. Non-listed companies may instead fall into three cases (medium-large, small and micro) and consequently have a sufficient financial statement disclosure with respect to the size. The diagram below summarizes the three types of financial statement for unlisted companies and consequently not subject to international accounting standards, but to the rules of the Civil Code and national accounting standards.

\begin{tabular}{|c|c|c|c|c|}
\hline Company type & Assets & Net revenues & $\begin{array}{c}\text { Average } \\
\text { employees }\end{array}$ & Financial statements \\
\hline $\begin{array}{l}\text { Medium-large } \\
\text { (Art.2423) }\end{array}$ & Over $4,400,000 €$ & $\begin{array}{l}\text { More than } \\
8,800,000 €\end{array}$ & 50 & $\begin{array}{l}\text { Balance Sheet } \\
\text { Income Statement } \\
\text { Notes to the accounts } \\
\text { Financial statements }\end{array}$ \\
\hline $\begin{array}{l}\text { Small } \\
\text { (Art.2435bis) }\end{array}$ & Up to $4,400,000 €$ & Up to $8,800,000 €$ & Up to 50 & $\begin{array}{l}\text { Balance Sheet } \\
\text { Income Statement } \\
\text { Notes to the accounts }\end{array}$ \\
\hline $\begin{array}{l}\text { Micro } \\
\text { (art.2435ter) }\end{array}$ & Up to $175,000 €$ & Up to $350,000 €$ & Up to 5 & $\begin{array}{l}\text { Balance Sheet } \\
\text { Income Statement }\end{array}$ \\
\hline
\end{tabular}

\section{Final Considerations}

The financial statement reflects the past, present and planned future management dynamics in the integration of economic quantity, estimates and conjecture. A true and fair financial statement constitutes therefore the starting point for information to appreciate and compare over time the degree of successful profitability and competitiveness of an entrepreneurial reality. Thanks to the financial statement one may then interpret the various composition in time of economic expectations of the institutional stakeholders in the company.

Truthful and correct information, stemming from a transparent financial statement, contributes over time together with long-term profitability - in increasing the consensus, collaborations and confidence which every enterprise needs to continue its activities according to affordability.

The company financial statement has undergone profound changes over time, transitioning from synthetic document, sometimes inscrutable therefore not very expressive of the corporate realities, to analytical and articulated document, which presents a wide range of both direct and indirect compulsory information, perhaps exhaustive but increasingly complex, intended for end-users (Consorti, 2001).

The European Union has launched a new process of harmonisation based on two differentiated paths. The first which has concerned firstly the consolidated financial statements of listed companies as well as other different cases depending on what is provided by the individual national regulations - has resulted in the obligation imposed by regulation, to draw up the financial statement in accordance with international accounting standards (IAS/IFRS). The second path - following from the realities excluded from the first path - provides instead a gradual convergence of accounting laws of the individual Member States to IAS/IFRS, through the instrument of the directives and of the consequent decrees to transpose the directive into national law (Sarcone, 2011).

The adoption of international accounting principles, able to integrate and clarify the laws governing the financial statements, represents a further contribution to the improvement of corporate information, certain in a corpus of divergent origin and nature. This introduction more than an evolution from the legislative point of view, is emerging as a "revolution from the practical point of view", which however is devoid of heuristic value to be considered in the same way as a scientific revolution (Canziani, 2016).

For the international accounting principles the financial statements are a tool that, while addressing a wide range 
of users, are intended primarily for investors. In this regulatory corpus the needs of certain categories of interest, such as for example that of creditors, traditionally protected by the doctrine of civil law, see their importance diluted (Piscitelli, 2012). In the context of a vision predominantly perspective of future data, the principle of prudence undergoes a shake up (Campedelli, 2004), which in the framework of IFRS is not on the same level as the principle of competence albeit subjected to it. The Anglo-Saxon logic therefore identifies a different meaning attributable to the realization principle, that from real becomes potential, since for the purposes of determining the income and capital, all operations occurring during the year and their virtual results are considered, although not actually and definitively produced in the period of time considered (Piscitelli, 2012).

Consequently there is no longer a profitability conception in the operating result, in which the effective management data are mainly covered, but a patrimonialistic notion wherein the result for the financial year is expressed as the value of assets and liabilities (Lionzo, 2012).

From the point of view of the accounting origins of the financial statement, perhaps it has gone back to the past. Since the framework of the document in accordance with the IFRS moves from the Anglo-Saxon patrimonialistic setting: the same that characterised the Code of 1942. On the other hand this patrimonialistic logic of IFRS was already present in Fabio Besta when the Venetian School teacher defined "positive components of profits as the value of each new addition of assets to property, any increase in the value of the assets owned, the value of each growth in receivables and of any decrease in payables; in short all asset mutations that occur in the values of those elements provided they are due only to the company's financial year. The value of every sale or loss of assets, any decrease in value of the receivables, any increase in that of payables, are negative components of profits; all mean the passive mutations found in the value of the elements of the matter. If the negative components surpass the positive, there is loss" (Besta, 1922).

We are therefore faced with a change of setting with the abandonment of the profitability theory? It is still too early to answer the question, given that all developments must first be tested in practice in order to be definitively assessed and then assert themselves. It will then be necessary to observe through a careful analysis of financial statements, the conduct by companies in applying the new standards and the most obvious divergence between the values calculated with the application of national rules and those arising from international principles.

The process of amending the technical and legal regulation of financial statements was developed in stages and is still in progress. This evolutionary phenomenon occurs, on the one hand through membership of our country to the European Union and the international community, on the other hand for the purpose of achieving a progressive harmonisation and standardisation of technical and legal systems in accounting, as a result of the widening of the areas of commercial exchange and technology sharing, with intersystemic mobility of capital and persons (Pontani, 2011).

As said, there are many trends and many projects are underway, therefore every attempt to arrive at a final evaluation clashes with the unforeseeable developments involving the political nature of the diffusion processes underway (Di Pietra, 2010).

What is certain is that the accounting principles through their nature are always in evolution in order to adapt to the changes in the economic context that they seek to represent. With this we want to highlight the necessary change in mentality: from a stationary or almost stationary scenario for many years (the one designed by the Community or national legislator), to one in continuous variation (that of accounting standards).

At the same time profoundly different financial statement regulation remains in Italy that does not promote the harmonization of accounting principles with the related benefits relating to the comparability of information and usefulness in favour of stakeholders (Azzali, 2015).

In the new vision of the financial statements, the accounting information must find a balance between the interests of the beneficiaries of the financial statements and that of the companies not to be excessively encumbered by the obligations of an informative nature with respect to the benefits generated. It follows that the new model of the financial statements be structured depending on the size of the companies, with particular attention to not burden the micro and small enterprises with activities that would require appropriate information systems, with consequent increase of costs that would certainly not be sustainable by most of them (D'Agostinis, 2013).

Indeed the information needs of individuals changes over time. It is therefore normal that various financial statement models come in succession and that there is no best accounting model in an absolute sense, excluding the historical moment in which it is proposed. In this perspective (Gray, Owen and Adams, 1996) the four 
models presented in the previous chapter must therefore be analysed.

In conclusion we want to emphasize how the financial statement information effectiveness does not improve with the increase of the amount of the information presented. If in fact the changes outlined are not strictly necessary, they end up confusing the recipient, who overwhelmed by the abundance of data conveyed, could get lost in the jungle, often cryptic, of items and values (Broglia Guiggi, 2004). So that the financial statement can express all its potential signage ability the quality of information should therefore improve and does not increase the amount, reconciling two opposite excesses, both harmful: (a) on the one hand, a pedantic and long-winded analyticity, dispersive and little incisive; (b) on the other hand, an extreme synthesis, often degenerating into an unreasonable, dark and counter-productive hermeticism (Broglia Guiggi, 2004).

Therefore, both the lack and the extreme wealth of news are information change factors. In the first case where information is omitted or what is due to submit the necessary clarifications is not done. In the second case where it achieves a confluence of information sometimes unnecessary or even specially misleading or, pejus, self-referential information aimed at emphasizing the positive aspects of the management and of the results, neglecting instead critical situations, sometimes even incumbent on business continuity (Poselli, 2015).

\section{References}

Azzali, S. (2015). Financial reporting and accounting standards.

Besta, F. (1922). La Ragioneria (2nd ed.). Vallardi, Milano.

Branciari, S., \& Poli, S. (2009). Il principio di rilevanza nella prassi dei bilanci italiani. Giappichelli, Torino.

Broglia, G. A. (2004). La funzione del bilancio d'esercizio tra evoluzione e tendenziale mutazione. Giappichelli, Torino.

Campedelli, B. (2004). Ragioneria internazionale. Principi contabili e bilancio delle imprese e dei gruppi. Giappichelli, Torino.

Canziani, A. (2016). The transition to IFRS in Italy and Elsewhere, or from Code Napoléon to the Devolution of Sovereignty. In Bensan D, Praquin N. (Eds.), IFRSs in a Global World.

Coda, V. (1986). Il rendiconto finanziario, in Coda V., Frattini G., Valutazioni di bilancio. Principi economici, norme civili, norme fiscali e direttive comunitarie (3rd ed.). Libreria universitaria editrice Venezia, Venezia.

Consorti, A. (2001). L'evoluzione della funzione informativa del bilancio d'esercizio. Dal conto del patrimonio al sistema delle informazioni. Giappichelli, Torino.

D'Agostinis, B. (2013). Riflessioni sulle novità introdotte dalla direttiva 2013/34/UE in materia di bilanzio di esercizio. Cacucci, Bari.

Di Pietra, R. (2010). Ragioneria contabile: dall'armonizzazione contabile al bilancio IFRS. Cedam, Padova.

Farneti, G. (2002). I flussi monetari nei processi di programmazione e controllo.

Ferrero, G. (1981). Bilancio di esercizio e amministrazione delle imprese.

Gray, R., Owen, D., \& Adams, C. (196). Accounting and accountability: changes and challenges in corporate social and environmental reporting.

Lionzo, A. (212). Gli studi di financial accounting di matrice nordamericana. Fondamenti epistemologici e percorsi scientifici.

MEF. (2014). Consultazione pubblica per l'attuazione della direttiva 2013/34/EU del Parlamento europeo e del Consiglio del 26 giugno 2013, relativa ai bilanci d'esercizio, ai bilanci consolidati e alle relative relazioni di talune tipologie di imprese.

Nicoliello, M. (2016). Il ruolo degli organismi contabili nella disciplina del bilancio d'esercizio.

Piscitelli, V. (2012). Il sistema unico integrato a supporto dei principi contabili internazionali IAS/IFRS.

Pontani, F. (2011). Il bilancio d'esercizio delle società di capitali. Accounting philosophy e conceptual framework.

Portalupi, A. (2015). Con la presentazione dei dati più informazioni sulle società.

Poselli, M. (2005). L'evoluzione del sistema informativo di bilancio.

Potito, L. (1980). Il rendiconto finanziario nelle imprese.

Pozzoli, A. (2015). Micro-società alla prova debutto. 
Sarcone, S. (2011). La formazione del bilancio annuale. Disciplina civilistica e principi contabili nei loro tratti significativi.

\section{Copyrights}

Copyright for this article is retained by the author(s), with first publication rights granted to the journal.

This is an open-access article distributed under the terms and conditions of the Creative Commons Attribution license (http://creativecommons.org/licenses/by/4.0/). 